\title{
SENSIBILIZAÇÃO À DIVERSIDADE LINGUÍSTICA ATRAVÉS DOS MÉTODOS VISUAIS: UM RELATO COM MIGRANTES E REFUGIADOS GRADUANDOS DA UFPR
}

\author{
Awakening to Languages through Visual Methods: an account of an \\ experience with UFPR undergraduate migrant and refugee students
}

\author{
Bruna Pupatto RUANO \\ Universidade Federal do Paraná \\ bruna.ruano@gmail.com \\ https://orcid.org/0000-0003-3595-8158 \\ Bruna Faria Martins FRANCISCO \\ Universidade Federal do Paraná \\ fmartins.bruna@gmail.com \\ https://orcid.org/0000-0002-8163-4018
}

\begin{abstract}
RESUMO: Nesta contribuição, refletimos sobre como a Sensibilização à Diversidade Linguística (SDL) (CANDELIER, 2003), aliada aos Métodos Visuais (MELO-PFEIFER \& SIMÕES, 2017; KALAJA \& MELO-PFEIFER, 2019), pode colaborar no desenvolvimento da competência plurilíngue e pluricultural (COSTE; MOORE; ZARATE, 2009) de migrantes e refugiados recém-ingressos na Universidade Federal do Paraná (UFPR). Para tanto, durante a disciplina Português: Práticas Textuais Acadêmicas, ofertada pelo curso de Letras para esse público, exploramos as biografias linguísticas dos discentes para que, primeiramente, eles se reconhecessem como sujeitos plurilíngues. Assim, ao final da atividade, os alunos puderam refletir sobre como essas línguas, que compõem seus repertórios linguísticos, podem auxiliá-los no aprimoramento da língua-alvo, neste caso, do português acadêmico.

PALAVRAS-CHAVE: Métodos Visuais; Migrantes e Refugiados; Sensibilização à Diversidade Linguística; Competência Plurilíngue e Pluricultural.
\end{abstract}

\begin{abstract}
This contribution reflected on how the Awakening to Languages (éveil aux langues) (CANDELIER, 2003), combined with Visual Methods (MELO-PFEIFER \& SIMÕES, 2017; KALAJA \& MELO-PFEIFER, 2019), can collaborate for the development of plurilingual and pluricultural competences (COSTE; MOORE; ZARATE, 2009) of newly admitted migrants and refugees at the Federal
\end{abstract}

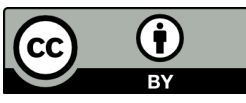


University of Paraná (UFPR). In order to do this, in the course Portuguese: Academic Textual Practices offered for this audience, the linguistic biographies of the students were explored so that they would firstly recognize themselves as plurilingual subjects. Thereby, at the end of the activity, students were able to reflect on how these languages that constitute their linguistic repertoire can assist them in improving a target language, which in this instance, is academic Portuguese. KEY WORDS: Visual Methods; Migrants and Refugees; Awakening to Languages; Plurilingual and Pluricultural Competence.

\section{INTRODUÇÃO}

O objetivo deste trabalho é, primeiramente, refletir sobre a utilização dos métodos visuais em aulas e pesquisas no campo da linguística aplicada. Além disso, pretendese apresentar e discutir o exemplo completo de uma atividade de desenho realizada no primeiro dia de aula de uma disciplina de português acadêmico - destinada a migrantes e refugiados calouros, matriculados em diversos cursos de graduação da Universidade Federal do Paraná (UFPR). Para tanto, a seguir, relataremos o contexto no qual este estudo foi desenvolvido. Posteriormente, teceremos algumas considerações relacionadas à Sensibilização à Diversidade Linguística (SDL) - uma das abordagens plurais para o ensino de línguas (CANDELIER et al., 2012). Em seguida, apresentaremos a metodologia utilizada neste trabalho e discorreremos sobre os métodos visuais no campo da didática das línguas. Logo após, apresentaremos uma descrição detalhada da aplicação da atividade juntamente com a análise dos desenhos produzidos. O texto encerra com uma síntese dos principais pontos elencados ao longo do trabalho, apresentando possíveis desdobramentos dentro desta temática para trabalhos futuros.

A atividade de desenho mencionada anteriormente foi desenvolvida no contexto da disciplina Português: Práticas Textuais Acadêmicas, ofertada pelo Departamento de Polonês, Alemão e Letras Clássicas (DEPAC) e faz parte das ações de acolhimento linguístico e acadêmico que visam o acompanhamento e a permanência de estudantes migrantes e refugiados na universidade. Trata-se de uma ação construída no âmbito do Programa Política Migratória e Universidade Brasileira (PMUB-UFPR) ${ }^{1}$, iniciado no ano

\footnotetext{
${ }^{1}$ Para mais informações sobre o Programa PMUB-UFPR, consultar Gediel \& Friedrich, 2020. Revista X, v. 16, n. 2, p. 437-460, 2021.
} 
de 2014, na UFPR. O PMUB-UFPR está vinculado à Cátedra Sérgio Vieira de $\mathrm{Mello}^{2}$, do Alto Comissariado das Nações Unidas para Refugiados - ACNUR, e tem a finalidade de: (i) desenvolver políticas de acolhimento e de (re)inserção de migrantes e refugiados nos cursos de graduação e pós graduação desta IES; (ii) realizar a revalidação de diplomas desse público-alvo de forma facilitada, além de (iii) trabalhar no direcionamento do fortalecimento da autonomia e da qualificação de migrantes, refugiados e apátridas através da formulação de políticas migratórias na instância universitária (ACNUR). Esse Programa conta, atualmente, com atividades de 8 cursos da instituição (Letras, Direito, Psicologia, Sociologia, Informática, História, Medicina e Comunicação) e recebe apoio do Ministério Público do Trabalho do Paraná, por meio de convênio firmado no ano de 2015.

O trabalho do PMUB-UFPR dos últimos anos culminou na proposta e aprovação de 4 importantes Resoluções destinadas exclusivamente à população migrante e refugiada: (a) Resolução 13/14: a primeira delas, diz respeito à reinserção acadêmica desse público na universidade, sem que seja necessário passar pelo processo seletivo tradicional, batizado de Programa Reingresso ${ }^{3}$; (b) Resolução 02/16: no ano de 2016 entra em vigor na UFPR a Resolução 02/16, esta, por sua vez, trata do processo de revalidação de diplomas desse público-alvo de forma facilitada, isto é, garantindo, mediante justificativa, alguma relativização das exigências tradicionais, como por exemplo a isenção das taxas cobradas. Graças a essa política, só no ano de 2019, mais de 20 migrantes e refugiados obtiveram seu diploma de nível superior revalidado pela UFPR; (c) Resolução 63/18: a terceira conquista do Programa se deu através da aprovação da Resolução 63/18, por meio da qual se institucionaliza o ingresso diferenciado - via vestibular especial, com a oferta de 10 vagas suplementares nos cursos de graduação da UFPR, - destinadas exclusivamente a migrantes e refugiados; (d) Resolução 56/19: finalmente, em março de 2020, entra em vigor a Resolução 56/19, que regulariza a implementação do Programa de Formação Suplementar: Ciclo de Acolhimento Acadêmico para Estudantes Refugiados - propondo políticas de permanência para esses discentes inseridos no espaço institucional da UFPR, dentre elas destaca-se a disciplina de português anteriormente mencionada.

Assim, a partir desse contexto, foram criadas, no ano de 2019, 4 disciplinas de Português Acadêmico (60h/cada) para dar conta desta demanda particular da instituição.

\footnotetext{
${ }^{2}$ A Cátedra Sérgio Vieira de Mello (CSVM), criada em 2003 pelo Alto Comissariado das Nações Unidas para Refugiados (ACNUR), tem como objetivo central promover a educação, pesquisa e extensão acadêmica voltada à população em condição de refúgio. No Brasil, a CSVM foi incorporada por diversas universidades: públicas e privadas e a UFPR é uma delas. Nos últimos anos, as instituições associadas têm apresentado resultados concretos do seu envolvimento com a causa dos refugiados, tanto no plano acadêmico como em aspectos de integração dessa população. ${ }^{3}$ Para maiores informações sobre o Programa Reingresso da UFPR, consultar Ruano, 2019.
} 
Os estudantes matriculados são alunos e alunas que, graças às políticas de ingresso diferenciado e de reinserção acadêmica, tiveram a possibilidade de iniciar seus estudos na UFPR e de cursarem disciplinas de português acadêmico desenhadas para esse fim. O público é muito heterogêneo, seja por suas línguas maternas (LM), pelo seu tempo no Brasil ou por suas nacionalidades: recebemos na universidade estudantes de muitos lugares do mundo, sendo os países mais expressivos o Haiti, a República Democrática do Congo, a Síria e a Venezuela. Contudo, somam-se ao grupo, estudantes provenientes da Guiné-Bissau, do Benin, do Peru, da Jordânia, do Congo, do Togo, entre outros. Esses sujeitos trazem para a UFPR uma pluralidade de línguas e culturas que se manifesta no espaço acadêmico tornando-o muito mais rico, diverso e democrático. Contudo, como professoras atuantes nesse contexto, temos nos questionado, nos últimos anos, sobre o nosso papel no trabalho em prol da sensibilização à essa diversidade junto à comunidade universitária e, também, junto aos próprios alunos matriculados em nossas disciplinas.

\section{A SENSIBILIZAÇÃO À DIVERSIDADE LINGUÍSTICA (SDL)}

Levando em consideração a diversidade e a bagagem linguística e cultural de nosso público-alvo, acreditamos que o trabalho com a SDL pode contribuir para o desenvolvimento da competência plurilíngue e pluricultural desses estudantes e de seus respectivos professores. Por esse motivo, é necessário, primeiramente, compreender o que estamos nomeando de competência plurilíngue e pluricultural (MELO-PFEIFER \& SCHIMDT, 2014; COSTE, MOORE \& ZARATE, 2009). De acordo com Coste, Moore \& Zarate (2009) podemos designá-la como:

la compétence à communiquer langagièrement et à interagir culturellement possédée par un acteur qui maitrise, à des degrés divers, plusieurs langues, et a, à des degrés divers, l'expérience de plusieurs cultures, tout en étant à même de gérer l'ensemble de ce capital langagier et culturel. L'option majeure est de considérer qu'il n'y a pas là superposition ou juxtaposition de compétences toujours distinctes, mais bien existence d'une compétence plurielle, complexe, voire composite et hétérogène, qui inclut des compétences singulières, voire partielles, mais qui est une en tant que répertoire disponible pour l'acteur social concerné. (COSTE; MOORE; ZARATE, 2009, p.11).

Dessa maneira, é fundamental que nossos alunos tenham, em primeiro lugar, consciência da complexa coexistência das línguas e culturas que fazem parte de seu repertório, de que seus saberes são heterogêneos e desequilibrados e ainda de que 
esses conhecimentos são utilizados de maneiras distintas a depender do contexto e propósito social.

Portanto, quando temos em sala de aula um público com essas especificidades, no nosso caso, migrantes e refugiados, é necessário que o professor faça um trabalho com os alunos que vise, de forma consciente, fomentar o respeito à multiplicidade linguística e cultural à qual os estudantes serão expostos, de modo a fazer com que o grupo seja mais receptivo não apenas às línguas e culturas de contato dentro da sala de aula, mas também fora dela, sensibilizando esse sujeitos, inclusive, para as subjetividades presentes no interior de cada indivíduo. Além disso, é essencial que o docente crie oportunidades no ambiente acadêmico para estimular atitudes positivas face às diversidades.

Para que esse trabalho seja realizado de maneira fundamentada, o professor pode embasar suas práticas nas Abordagens Plurais (CANDELIER et al., 2012), que dizem respeito a "approches didactiques mettant en ouvre des activités d'enseignementapprentissage qui impliquent à la fois plusieurs (= plus d'une) variétés linguistiques et culturelles." (CANDELIER; DE PIETRO, 2012, p.7).

Assim, as abordagens plurais consideram o repertório linguístico dos alunos como um todo, sendo, portanto, fundamentais no desenvolvimento da competência plurilíngue e pluricultural dos estudantes, pois os auxilia a refletir sobre a língua-alvo e a desenvolver a capacidade de relacioná-la a outras línguas que já fazem parte de seu acervo pessoal. (CANDELIER et al., 2012). Dessa maneira, os estudantes são levados a construir saberes sobre diferentes línguas-culturas a partir do desenvolvimento de capacidades metalinguísticas, metacomunicativas e metacognitivas, as quais, por sua vez, facilitam o aprendizado de novas línguas.

Dentre as abordagens plurais, a saber: l'éveil aux langues, l'intercompréhension entre les langues parentes, l'approche interculturelle e la didactique intégrée des langues apprises (CANDELIER, 2003; CANDELIER \& DE PIETRO, 2012; CANDELIER et al., 2012), consideramos que l'éveil aux langues, ou seja, a Sensibilização à Diversidade Linguística (SDL), é a que melhor se enquadra nos objetivos do presente trabalho.

Embora esta abordagem seja mais utilizada em ambientes escolares, com o público infantil, acreditamos ser perfeitamente possível transpor as reflexões oriundas desse contexto para o público adulto com o qual trabalhamos. Pois, segundo Candelier \& de Pietro (2012), a SDL pode também ser utilizada como uma ferramenta de acompanhamento ao longo do percurso de ensino-aprendizagem de línguas de estudantes em geral. Assim, consideramos a SDL como uma das possíveis chaves de nossas práticas pedagógicas, já que, de acordo com os autores mencionados, essa abordagem é a que tem maior enfoque 
na diversidade linguística e cultural. Nesse sentido, a SDL serve como ferramenta para auxiliar a promoção da valorização das línguas-culturas dos estudantes, da diversidade e de atitudes de respeito face às diferenças.

Pensando em práticas pedagógicas e metodologias que visem ao trabalho da SDL com um público tão heterogêneo como o nosso, o qual não compartilha da(s) mesma(s) língua(s) materna(s), encontramos nos métodos visuais (MELO-PFEIFER \& SIMÕES, 2017; KALAJA \& PITKÄNEN-HUHTA, 2018; KALAJA \& MELOPFEIFER, 2019) um interessante dispositivo para nos auxiliar nas práticas de sala de aula. Assim, na próxima seção, traremos algumas reflexões que dizem respeito ao uso dos métodos visuais no ensino de línguas.

\section{METODOLOGIA}

Levando em consideração a diversidade linguística de nosso grupo de alunos, optamos por utilizar, neste estudo, os métodos visuais como uma possibilidade não verbal de dar visibilidade aos relatos de nossos estudantes. Esses relatos consistiam na representação de seus repertórios linguístico-culturais, ou seja, de suas biografias linguísticas. De acordo com Molinié (2006):

La biographie langagière repose sur la capacité de l'individu à relater les éléments constitutifs de son expérience dans les domaines linguistique et culturel. L'hypothèse qui traverse ce numéro est que ce travail biographique permet de développer chez l'apprenant de langues la conscience selon laquelle ses apprentissages linguistiques gagnent à être mis en relation les uns avec les autres. Parce qu'elles permettent de penser les langues comme les éléments inter - reliés dans l'histoire, le répertoire culturel et le bouquet plurilingue du sujet, les biographies langagières contribuent à nourrir la réflexion menée actuellement en didactique, sur le plurilinguisme.(MOLINIÉ, 2006, p.8).

Salientamos que o processo de realização de uma (auto)biografia linguística favorece a reflexão sobre o sujeito em si, que conta sua trajetória de vida através das línguas que o constituem e de suas representações, se reapropriando de sua história linguística (PERREGAUX, 2002).

No caso específico do público migrante, Molinié (2019) ainda destaca que, através da narrativa autobiográfica, eles podem renegociar sua autoimagem de sujeito plurilíngue em movimento, tendo a possibilidade de compor, articular e reconfigurar suas aspirações sociais e identitárias em uma identidade complexa. 
Além disso, no campo das ciências humanas, a autobiografia está associada a uma metodologia de pesquisa de cunho qualitativo que se justifica por "un intérêt pour la perspective personnelle des sujets à l'étude, un besoin d'analyser les phénomènes de manière holistique ainsi qu'une volonté de saisir des subtilités (p. ex. contextuelles) qui échappent aux analyses quantitatives" (SMUK, 2016, p. 139 apud KUCHARCZYK \& SZYMANKIEWICZ, 2019, p. 82).

Assim, a seguir, justificamos o motivo pelo qual nos apoiamos nos métodos visuais para a realização deste estudo. Na sequência, apontamos as questões de investigação que nortearam este trabalho, traçamos o perfil dos participantes e, por fim, relatamos o percurso da aplicação da atividade que proporcionou esta pesquisa.

\section{Os Métodos Visuais no campo da didática das línguas}

Conforme iremos explorar nesta seção, as narrativas visuais podem ser aplicadas, principalmente, junto a um público que não compartilha a mesma língua materna dos pesquisadores, ou, ainda, no caso de os informantes possuírem um conhecimento reduzido do idioma em que a pesquisa ocorre (MELO-PFEIFER \& SCHMIDT, 2019).

Neste trabalho, em consonância com Melo-Pfeifer \& Simões (2017), iremos nos referir aos métodos visuais como um conjunto de procedimentos e modalidades de geração de dados, como, por exemplo: desenhos ou narrativas visuais, histórias digitais, "memes"/montagens, fotografias, entre outros, que podem, ou não, "serem combinados e articulados com métodos/recursos mais estabelecidos" como fonte de informação na investigação (MELO-PFEIFER; SIMÕES, 2017, p. 18).

A valorização dos métodos visuais nas pesquisas de ensino-aprendizagem de línguas nos últimos anos é visível (MELO-PFEIFER \& SIMÕES, 2017, KALAJA \& MELO-PFEIFER, 2019; MELO-PFEIFER \& SCHMIDT, 2019) e esse recurso vem sendo utilizado na paisagem metodológica de diversas investigações da área. Segundo MeloPfeifer \& Simões (2017, p.18), isso ocorre, de alguma maneira, pela "tentativa de acesso ao sujeito na sua integralidade e na sua complexidade, por vezes difíceis de descrever, de se escrever e de se representar verbalmente".

Na perspectiva das autoras, além do já conhecido "narrative turn" (PAVLENKO, 2007, apud MELO-PFEIFER \& SIMÕES, 2017), o qual valoriza o componente linguístico e discursivo na pesquisa, já bastante utilizado e reconhecido na área da didática das línguas, podemos também agregar às nossas investigações o "visual turn" (KALAJA \& PITKÄNEN-HUHTA, 2017, apud MELO-PFEIFER \& SIMÕES, 2017) que revela elementos narrativos com outros recursos semióticos com o intuito de historiar Revista X, v. 16, n. 2, p. 437-460, 2021. 
as experiências vividas. Desta forma, em ambos os casos, "a atração pelo vivido e pela forma como o sujeito reconstrói e "narra" as suas experiências são os grandes focos de atração" (MELO-PFEIFER \& SIMÕES, 2017, p.18).

Melo-Pfeifer \& Schmidt (2019, p. 58, 59), em seu artigo intitulado "Integration as Portrayed in Visual Narratives by Young Refugees in Germany", apontam algumas vantagens para a utilização das narrativas visuais como método de pesquisa junto à população migrante e refugiada, a saber:

(i) A utilização de desenhos, além de permitir que o pesquisador acesse as representações da vida e das línguas dos participantes da pesquisa, ainda os preserva de situações desconfortáveis que podem vir a ocorrer através da utilização de uma língua estrangeira;

(ii) Os métodos visuais podem ser considerados pouco invasivos, já que a presença de uma terceira pessoa, como mediadores ou tradutores - e de suas possíveis deturpações de sentido - não se faz necessária;

(iii) A "voz multimodal", que se faz presente nas narrativas visuais, pode promover a autoestima dos participantes e auxiliá-los na reflexão sobre suas próprias identidades.

Com relação à "voz multimodal”, Melo-Pfeifer \& Simões (2017) chamam a atenção para o fato de que os desenhos/narrativas visuais abrem espaço para outros componentes que não fazem parte dos elementos verbais propriamente ditos.

Assim, a partir das narrativas visuais, é possível acessar as representações que os estudantes têm sobre as línguas com as quais têm contato e, além disso, podem ilustrar a relação do sujeito com a aquisição ou a aprendizagem dos idiomas que compõem sua biografia linguística.

\section{Questões de investigação}

A atividade que embasa este estudo consiste, primeiramente, em investigar a consciência metalinguística dos alunos, através da representação de seus repertórios linguístico-culturais. Assim, para que pudéssemos avaliar de que maneira trabalharíamos a SDL ao longo do semestre, nos guiamos por algumas perguntas orientadoras para analisar os desenhos produzidos em sala de aula. Dessa maneira, buscamos responder às seguintes questões:

- Que línguas são representadas nos desenhos (língua materna, língua oficial, línguas regionais, etc.)? 
- Como essas línguas são representadas (apenas com desenhos, com palavras, frases, em que língua são as palavras/frases?)

- Existe uma hierarquia entre essas línguas? Se sim, em qual ordem?

- Quais ambientes são associados às línguas representadas?

- Alguma emoção é associada às línguas representadas? Quais?

\section{Participantes da pesquisa}

Os participantes desta pesquisa ${ }^{4}$ são alunos matriculados na disciplina Português: Práticas Textuais Acadêmicas I (HPAC0550), ofertada no primeiro semestre de 2020, pelo Departamento de Polonês, Alemão e Letras Clássicas (DEPAC), com carga horária de 60h.

O público é composto por 11 estudantes provenientes de 5 países distintos: Haiti (5), República Democrática do Congo (2), Síria (1), Togo (1) e Venezuela (2). Deste total, $40 \%$ são mulheres e $60 \%$ homens. Esses estudantes estão matriculados nos seguintes cursos da UFPR: Administração (3), Agronomia (1), Ciência da Computação (2), Ciências Econômicas (2), Direito (2) e Farmácia (1).

Para a análise deste trabalho foram selecionados uma amostragem de 5 desenhos que serão examinados a seguir. A escolha se deu, principalmente, pelos seguintes motivos: (i) para considerar as nacionalidades ${ }^{5}$ da maior parte dos alunos representados na turma: Venezuela, Síria, Haiti e República Democrática do Congo; (ii) para contemplar atividades dehomens emulheres; (iii) pela inteligibilidade dos desenhos e ainda, (iv) por considerarmos que essas 5 narrativas visuais são as que melhor ilustram os propósitos da atividade.

\section{A aplicação da atividade}

A atividade exemplificada neste artigo foi aplicada por duas professoras - autoras deste texto - no primeiro dia de aula (10/03/2020) da disciplina Português: Práticas Textuais Acadêmicas I. A tarefa consistiu em entregar aos alunos uma folha A4 em branco, lápis de cor e canetinhas e pedir que desenhassem as línguas que compõem suas histórias de vida, ou seja, sua biografia linguística.

\footnotetext{
${ }^{4}$ Salientamos nossa preocupação concernente à ética da pesquisa durante o processo de geração e análise dos dados. Assim, todos os participantes foram informados sobre os objetivos deste estudo. Esclarecemos que sua participação não era obrigatória e que seus nomes não seriam revelados, sendo substituídos por pseudônimos, de forma a ter seu sigilo assegurado. Além disso, todos os participantes assinaram um Termo de Consentimento Livre e Esclarecido, através do qual autorizaram a utilização dos seus desenhos para esta publicação.

${ }^{5}$ Infelizmente o desenho do aluno do Togo não pôde ser utilizado em função de sua baixa resolução no formato digital.
}

Revista X, v. 16, n. 2, p. 437-460, 2021. 
A ideia inicial do exercício era realizá-lo sem muitas instruções, para verificar qual era a consciência linguística dos alunos em um primeiro momento. A mesma atividade seria retomada no final do semestre, após o trabalho realizado com base nas abordagens plurais ao longo do curso. Porém, como já era possível prever que a reaplicação não seria possível em função do cancelamento iminente das aulas - devido ao momento atual global da pandemia do coronavírus - a atividade já foi utilizada como uma forma de sensibilização ao tema. Assim, foi solicitado aos alunos que refletissem sobre as línguas que compõem suas trajetórias, mesmo que não se considerassem 'fluentes'. O importante, para a atividade, era que representassem, em suas narrativas visuais, as línguas que tivessem algum tipo de valor em sua história e constituição como sujeito.

Em um segundo momento, de interação em sala, foi passada a palavra aos estudantes para que apresentassem seus desenhos para a turma e para que colocassem a sua biografia linguística em palavras. Paralelamente à apresentação, uma professora tomava notas em seu diário de campo.

Como finalização da atividade, e para iniciar o trabalho com a prática textual escrita, foi solicitado ainda aos alunos que escrevessem um texto, tendo como base suas narrativas visuais, sobre seu repertório linguístico-cultural.

\section{ANÁLISE DOS DESENHOS}

A seguir, apresentaremos e discutiremos, os resultados advindos da geração de dados relativos à atividade anteriormente descrita. De posse dos registros, buscamos analisá-los, com o intuito de obter direcionamentos para responder às perguntas de pesquisa mencionadas previamente.

Para que obtivéssemos uma análise mais cautelosa, cada uma das pesquisadoras respondeu às questões de investigação de forma individual, para, em seguida, discutirem e compartilharem suas sínteses, as quais se encontram compiladas a seguir. Além disso, quando necessário, fizeram uso das anotações coletadas no momento da apresentação oral dos alunos, presentes no diário de campo de uma das pesquisadoras. Trata-se, assim, de uma análise de cunho interpretativo e qualitativo (BORTONI-RICARDO, 2008) sendo, portanto, de caráter subjetivo.

A seguir, faremos a descrição e análise dos 5 desenhos selecionados. 


\section{Desenho 1}

$\mathrm{Na}$ imagem 1, podemos observar que Angela ${ }^{6}$ ilustrou sua biografia linguística de forma cronológica, traçando o percurso das línguas que foram sendo adicionadas ao seu repertório através do tempo. Podemos perceber também que, embora a estudante utilize símbolos, imagens e palavras para representar alguns idiomas, outras línguas não aparecem identificadas - tendo sido reveladas apenas quando a aluna apresentou seu desenho oralmente para a turma. Seguindo a ordem cronológica da narrativa, temos o espanhol como língua materna, utilizada nos contextos familiar e escolar, sendo representada pela palavra "hola" e, também pelas cores da bandeira da Venezuela, país de origem da estudante.

Imagem 1: desenho 1, Angela, venezuelana.

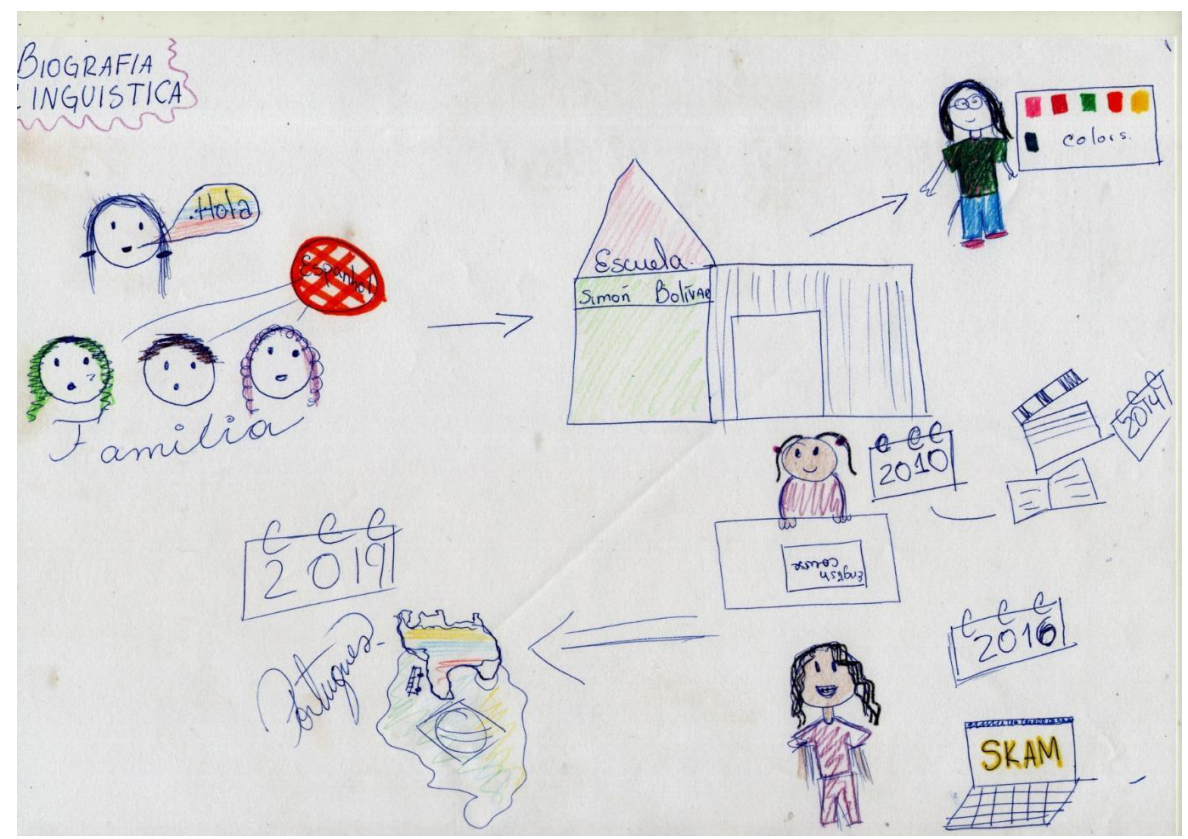

\#PraCegoVer: Desenho colorido. No canto superior esquerdo o título Biografia Linguística. Abaixo, o rosto de uma menina e um balão com a fala Hola. Abaixo o rosto de três pessoas, a palavra família e um círculo preenchido com traços vermelhos e com a palavra Espanhol. À direita da família, uma flecha indica a Scuela Simón Bolívar e acima da escola o desenho de uma professora e de uma lousa com quadrados coloridos e a palavra colors. Abaixo da escola desenho de uma menina sorrindo em uma carteira, sobre a carteira um livro com o título English Course, ao lado um calendário marca 2010. À esquerda, desenho de um livro aberto, de uma claquete de cinema e o calendário 2014. Abaixo, o calendário 2016 e um computador com a palavra SKAN na tela, à esquerda a menina em pé, ela está bem sorridente. Mais à esquerda, uma flecha indica as bandeiras coloridas da Venezuela e do Brasil, acima o calendário 2019 e a palavra português.

${ }^{6}$ Conforme exemplificado anteriormente, todos os nomes utilizados neste estudo são fictícios para preservar a identidade dos participantes da pesquisa.

Revista X, v. 16, n. 2, p. 437-460, 2021. 
A língua inglesa também aparece representada de forma escrita (colors e english course), tendo sido associada ao ambiente escolar, tanto pelas palavras quanto pela representação dos desenhos: carteira da escola, livros, cadernos e a própria escola. Percebemos também que houve contato com o inglês em dois momentos distintos da sua vida: primeiramente na Educação Básica (2014) e, em seguida, em um curso de inglês privado (2016).

Entre os anos de 2010 e 2014, temos a representação de filmes, sugerindo que Angela teve contato com algum outro idioma nesse período, mas não indicando qual, ou quais. Em sua apresentação oral do desenho, ela explicou que se tratava do francês e do russo, línguas com as quais teve contato apenas através de filmes, sem qualquer estudo formal.

Em 2016 ela relata ter se aproximado de uma outra língua (o norueguês) a partir de uma série de televisão chamada SKAN que a motivou a estudar esse idioma pela internet apenas pelo prazer, batizando-o como sua "língua de estimação".

Por fim, já em 2019, ano em que ela imigrou para o Brasil, se deparou pela primeira vez com a língua portuguesa, idioma que segue estudando desde então. A representação desse processo migratório se dá através do desenho do mapa que ilustra a fronteira entre a Venezuela e o Brasil, ambos os países identificados por suas bandeiras.

Percebemos, ainda, que Angela representou suas emoções, relacionadas às línguas, com a autorrepresentação de meninas sorrindo, indicando que teve boas experiências linguísticas.

\section{Desenho 2}

Na imagem 2 há algo que, de início, nos chama a atenção. A aluna Maria mobilizou uma "língua" utilizada em brincadeiras de criança para se apresentar: em espanhol é a 'língua do Fi', em português temos como equivalente a 'língua do P'. A estudante uniu a 'língua do Fi' ao espanhol (yo soy), sua língua materna, e ao português para se apresentar. Embora não seja uma língua 'oficial', é interessante perceber que ela a escolheu também para ser ilustrada na sua biografia linguística, o que é algo bastante curioso. Para representar sua língua materna, a aluna faz uma alusão ao seu país com a ilustração do mar, do sol e de uma ponte - de acordo com a estudante, se trata de uma paisagem da qual ela sente saudades e que é representativa de seu país (Rio Orinoco, na Ciudad Bolívar - cidade natal de Maria).

Logo abaixo podemos observar um coração vermelho ao lado da palavra "Jabibi". Segundo a aluna, ela gostaria de mostrar que conhece algumas palavras em árabe, língua materna de uma das estudantes do grupo, e escolheu a palavra 'amor' (habib) para Revista X, v. 16, n. 2, p. 437-460, 2021. 
exemplificar esse contato. É interessante observar que Maria grafou a palavra árabe com base na fonética do espanhol, com o 'J' no lugar do 'H'.

Assim como no desenho de Angela, o inglês aparece representado com uma cor e a palavra 'blue', sendo uma língua aprendida/estudada na escola. Associada a essa língua, a aluna desenhou um ' $X$ ', indicando que não gostava de estudá-la.

Maria representa o português com o mapa do Brasil, além disso, faz uma comparação com o espanhol desenhando uma cadeira e escrevendo o léxico referente a esse objeto em cada uma das línguas. O ponto de interrogação entre os desenhos da cadeira indica, de acordo com a aluna, a falta de proficiência que ela tinha no português ao chegar no país.

Imagem 2: desenho $2^{7}$, Maria, venezuelana.

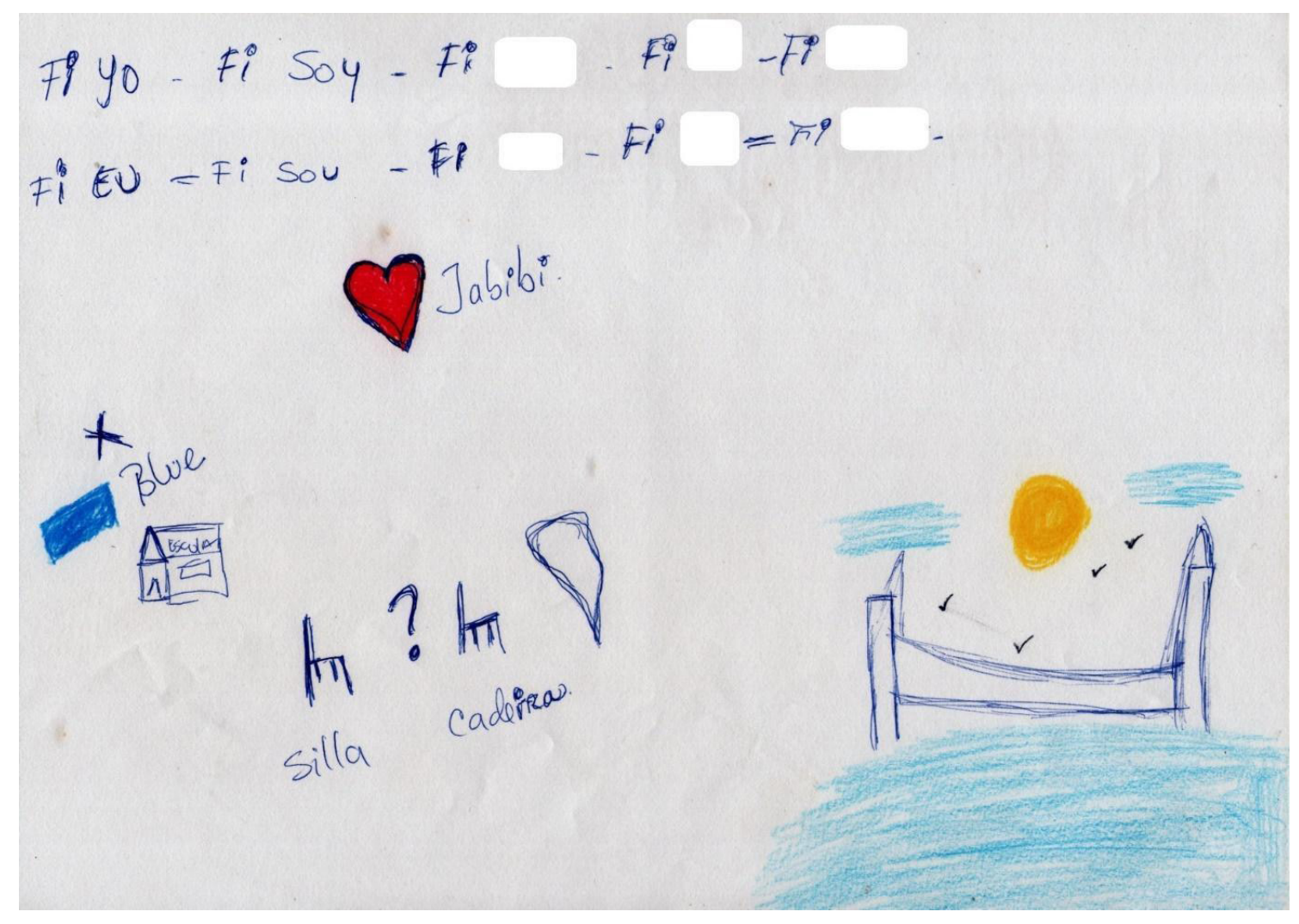

\#PraCegoVer: Desenho na cor azul e algumas imagens coloridas. Acima, da esquerda para a direita as palavras Fi Yo - Fi Soy e Fi Fi Fi seguidas de retângulos brancos. Abaixo Fi Eu - Fi Sou e Fi Fi Fi seguidas de retângulos brancos. Abaixo um coração vermelho e a palavra jabibi. Mais abaixo, à esquerda, um X, um retângulo azul, a palavra blue e o desenho de uma escola. Um pouco à direita e abaixo, o desenho de duas cadeiras e um ponto de interrogação entre elas. Embaixo da primeira cadeira a palavra silla e da segunda a palavra cadeiras. No canto inferior direito o desenho de uma ponte sobre um rio de cor azul, algumas gaivotas pelo céu, um sol bem forte na cor laranja e nuvens azuis.

${ }^{7}$ Os retângulos em branco foram inseridos no desenho pelas professoras para não identificar a aluna. Revista X, v. 16, n. 2, p. 437-460, 2021. 


\section{Desenho 3}

Assim como Angela, Jean também ilustra sua biografia linguística (imagem 3) a partir de sua trajetória cronológica, associando-a aos ambientes pelos quais circula/ circulava e aos contextos sociais que fazem parte de sua vida. $\mathrm{O}$ aluno ainda retrata as diferentes posições que as línguas ocupam ao longo do tempo em cada tipo de contexto comunicativo. Sendo assim, o primeiro local representado é a casa, o ambiente familiar, no qual ele usa, em primeiro lugar, o crioulo haitiano, sua língua materna. $O$ francês também é utilizado nesse ambiente, mas em $2^{\mathrm{a}}$ posição.

A seguir, Jean representa, de forma hierárquica, as línguas associadas ao ambiente escolar, sendo a primeira o francês, idioma oficial do país e, consequentemente, da educação formal. Em seguida, temos o crioulo, a primeira língua de comunicação utilizada na sociedade e, portanto, entre os colegas. Em $3^{\text {a }}$ posição aparece o inglês. $\mathrm{O}$ aluno menciona ainda o português e o espanhol, idiomas com os quais ele também teve algum contato durante sua vida escolar.

Imagem 3: desenho 3, Jean, haitiano.

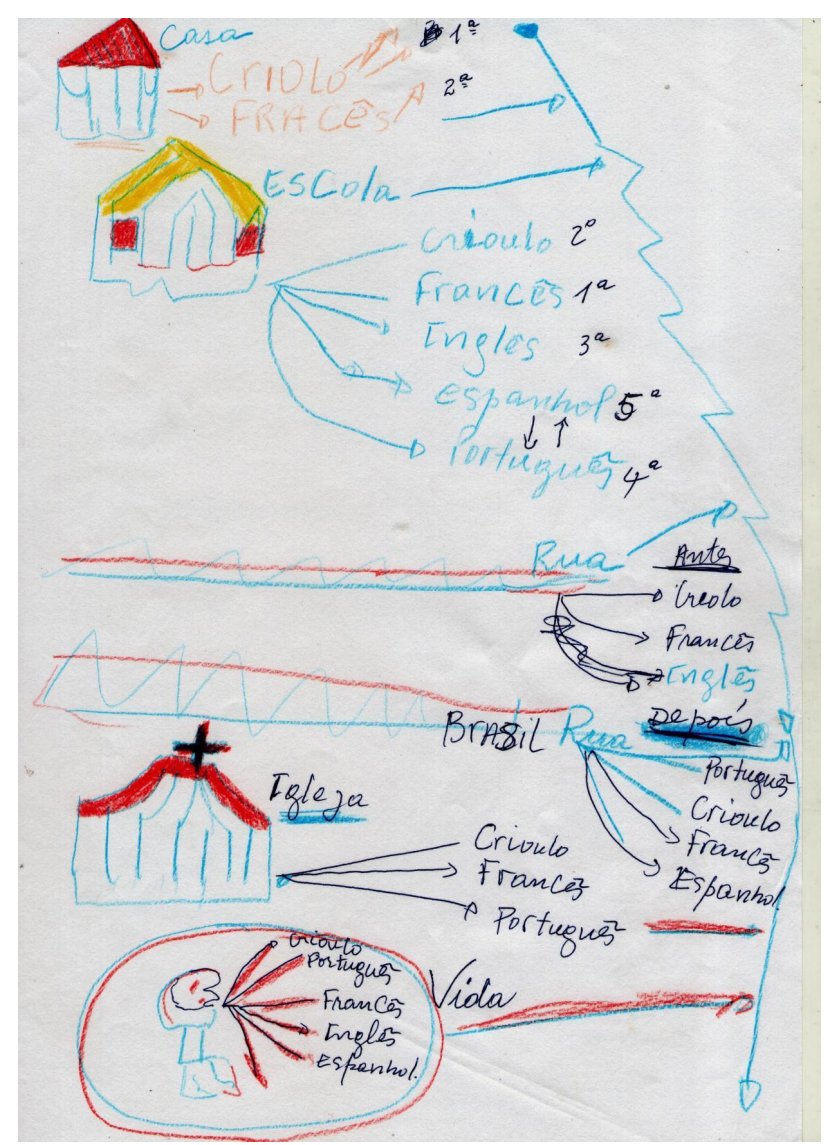


\#PraCegoVer: Desenho na cor azul, detalhes em vermelho. Canto superior esquerdo uma casa, ao lado as palavras crioulo $1^{\mathrm{a}}$. e francês $2^{\mathrm{a}}$. À direita, uma linha azul na vertical percorre por toda a folha. Abaixo da casa e ligeiramente à direita, uma escola e flechas indicando crioulo $2^{\mathrm{a}}$, francês $1^{\mathrm{a}}$, inglês $3^{\mathrm{a}}$, espanhol $5^{\mathrm{a}}$, português $4^{\mathrm{a}}$. Abaixo, da esquerda para a direita, uma rua indicando as palavras antes, crioulo, francês e inglês. Logo abaixo, a rua continua e num determinado ponto mostra a palavra Brasil, mais à direita as palavras português, crioulo, francês e espanhol. Lado esquerdo e mais abaixo, uma igreja e as palavras crioulo, francês e português. No centro inferior da folha, um círculo com um menino e várias flechas indicando crioulo, português, francês, inglês e espanhol. À direita a palavra vida e uma flecha em vermelho, na horizontal encontra o fim da linha azul.

Continuando sua trajetória, a representação é da 'rua', ou seja, das situações comunicativas presentes no cotidiano. E, aqui, Jean faz uma distinção da posição que as línguas ocupavam em sua vida antes de sua chegada no Brasil e após sua instalação nesse país. No Haiti, a primeira língua de comunicação era o crioulo, seguida pelo francês e, em $3^{\circ}$ lugar, o inglês.

No Brasil houve uma mudança e o português passou a ocupar o primeiro lugar na hierarquia das línguas, sugerindo que o aluno esteja imerso na sociedade brasileira, interagindo em contextos comunicativos diversos. O crioulo passa, então, a ser a segunda língua utilizada, indicando que, embora Jean desempenhe um papel ativo nessa nova sociedade, ele ainda mantém contato com a comunidade haitiana. Em terceiro e quarto lugar aparecem, respectivamente, o francês e o espanhol, provavelmente as línguas utilizadas com os colegas migrantes de outras nacionalidades. Já o inglês não é mais ilustrado, não fazendo parte, portanto, de situações cotidianas no país de acolhimento.

O próximo ambiente ilustrado é a igreja, onde o crioulo prevalece sobre o português, uma vez que já existe em Curitiba, cidade onde o aluno mora, cultos em crioulo. No entanto, segundo a apresentação oral do estudante, a bíblia utilizada é em francês. O português aparece em terceira posição por Jean frequentar, esporadicamente, segundo seu relato, cultos em língua portuguesa.

Por fim, o aluno faz um resumo das línguas que fazem parte de seu repertório linguístico na sua vida como um todo.

\section{Desenho 4}

$\mathrm{Na}$ imagem 4, é possível perceber que a representação da biografia linguística de Nádia também se dá de forma cronológica, no entanto, sem a presença de datas. A aluna utiliza as árvores e seus frutos/flores para ilustrar as línguas que vão fazendo parte de sua trajetória ao longo do tempo (representada também por um caminho). Segundo a apresentação oral da estudante, cada novo fruto/flor seria uma nova língua aprendida/ adquirida, contribuindo para seu crescimento pessoal e profissional. Ao final do desenho, a estudante ilustra, ainda, cada língua em um degrau, constituindo uma escada que pode Revista X, v. 16, n. 2, p. 437-460, 2021. 
ser associada à expressão "subir na vida", de forma que as línguas a ajudam a obter o sucesso. Assim, podemos inferir que a aluna associa a adição de novas línguas ao seu repertório a melhores oportunidades, ou seja, possui uma visão de língua como capital.

$\mathrm{Na}$ imagem, tanto a primeira árvore quanto o primeiro degrau representam a língua materna de Nádia, o árabe, o qual também aparece ilustrado de forma escrita por uma frase. Em sua apresentação oral, a estudante a traduziu para a turma: "a língua árabe é a minha língua materna".

$\mathrm{Na}$ escola, representada pelo edifício e um livro, sua árvore adquiriu novas flores (línguas), ilustradas em vermelho, com a aprendizagem do inglês e do francês. Em seguida, a árvore ganha mais uma flor, que pode ser associada ao português, também presente em um dos degraus.

É possível observar que o português não representa o último degrau, de forma que podemos inferir que Nádia ainda planeja aprender outras línguas. Da mesma maneira, na última árvore, há a representação de quatro flores vermelhas (árabe, inglês, francês e português) e dois frutos pretos que podem ser associados, como no caso dos degraus, às línguas que farão parte de seu futuro e que ela ainda desconhece quais sejam.

Interessante notar que no desenho da aluna síria as línguas são representadas com flores, coincidentemente, como verificamos na literatura da área. No âmbito da SDL, a construção de biografias linguísticas esteve desde sempre associada à ideia de "flor das línguas" - atividade de sensibilização à diversidade linguística, onde cada criança indica os nomes das línguas que conhece ou fala (ou ainda que gostariam de aprender) em várias pétalas para a produção de flores. O propósito dessa atividade é fazer com que os alunos reconheçam e legitimem o conhecimento linguístico das crianças do grupo em outras línguas para além da língua de instrução. (ARMAND \& MARAILLET, 2013). 
Imagem 4: desenho 4, Nádia, síria.

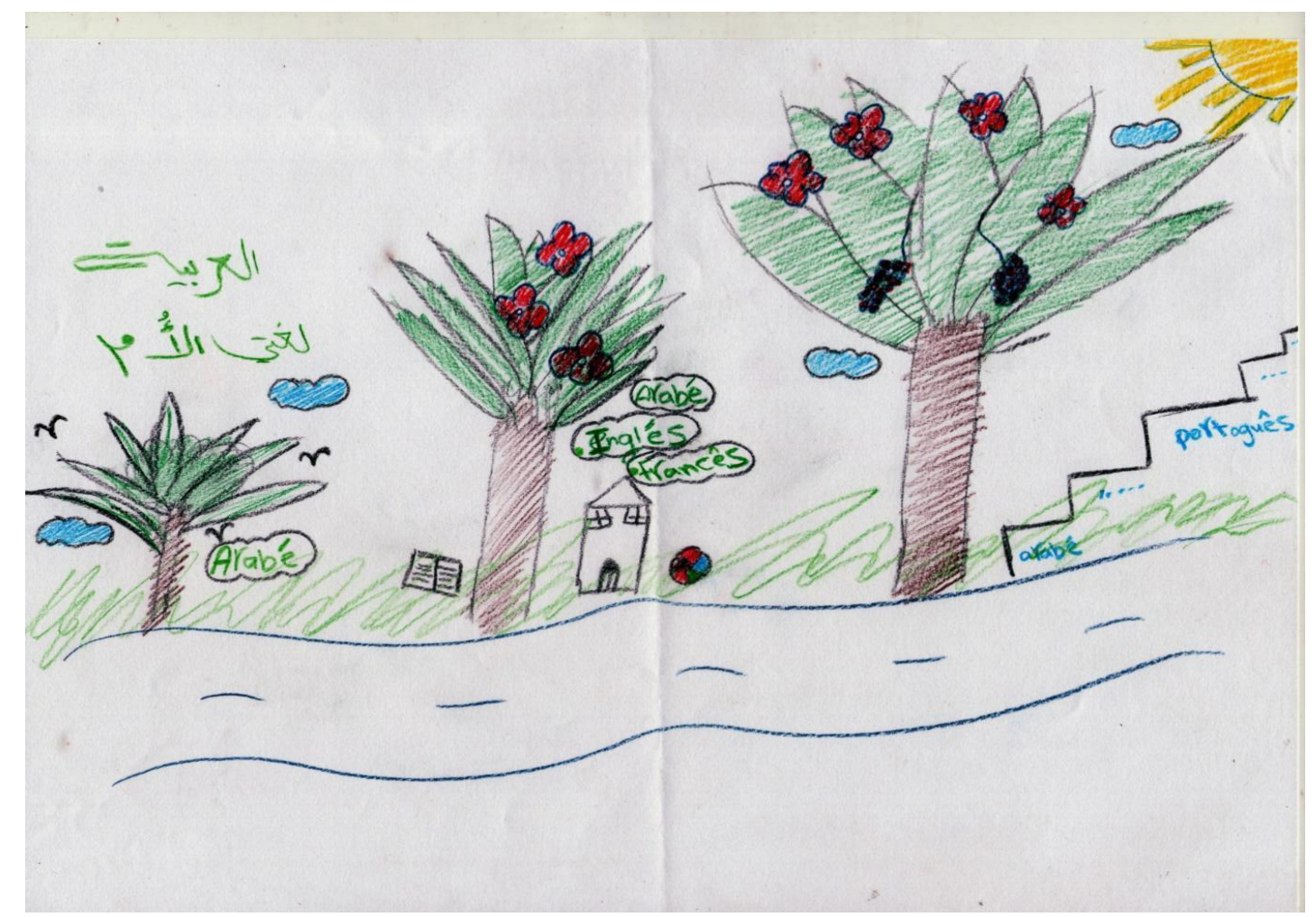

\#PraCegoVer: Desenho colorido. Da esquerda para a direita aparecem três árvores uma pequena, uma média e uma grande, ambas com tronco marrom e galhos verdes. Abaixo das árvores uma rua cruza toda a folha e à direita, após a terceira árvore uma escadaria com cinco degraus, no primeiro degrau a palavra árabe e no terceiro português, nos demais aparecem pontinhos. Acima da primeira árvore uma frase em árabe, algumas gaivotas e nuvens pelo céu, embaixo dos galhos à direita está escrito: árabe. A segunda árvore tem três flores vermelhas entre os galhos, à sua esquerda um livro e à direita uma casa, uma bola e está escrito: árabe, inglês e francês. A terceira árvore tem quatro flores vermelhas entre os galhos e dois brotos pretos. Nuvens no céu e uma parte do sol no canto superior direito.

\section{Desenho 5}

No desenho de Judith (imagem 5), também temos a representação da biografia linguística de forma cronológica.

Inicialmente, a aluna ilustra seu nascimento com uma data (22 de abril) e um pequeno diálogo em francês entre seus pais, simbolizando, provavelmente, uma de suas línguas maternas.

Em seguida, há, em ambiente escolar (desenhos de cadeiras, alunos, quadro, professor), a representação do inglês com a palavra 'hello'. Além disso, Judith faz uso 
da escrita para explicar que esse fragmento do desenho se tratava de um curso de inglês iniciado quando ela tinha 10 anos.

A próxima língua ilustrada é o espanhol, também associada a uma frase explicativa e sem representação de aprendizagem formal, sendo ilustrada por uma praia e tendo sido adquirida em uma estadia que ela teve em Cuba, país de língua espanhola.

Finalmente, a representação é da língua portuguesa, com a ilustração da UFPR e uma explicação por escrito sobre esse momento de sua vida.

É interessante salientar que a aluna não fez nenhuma alusão às línguas locais de seu país de origem, mencionando, apenas na apresentação para os colegas, que teve contato com as línguas tshiluba e lingala no ambiente familiar e ainda swahili e kikongo na sua comunidade local. Dessa maneira, podemos inferir que ela representou apenas as línguas com maior prestígio social em seu desenho, hierarquizando-as e, possivelmente, não considerando que essas outras tenham estatuto de língua.

Imagem 5: desenho 58, Judith, República Democrática do Congo.

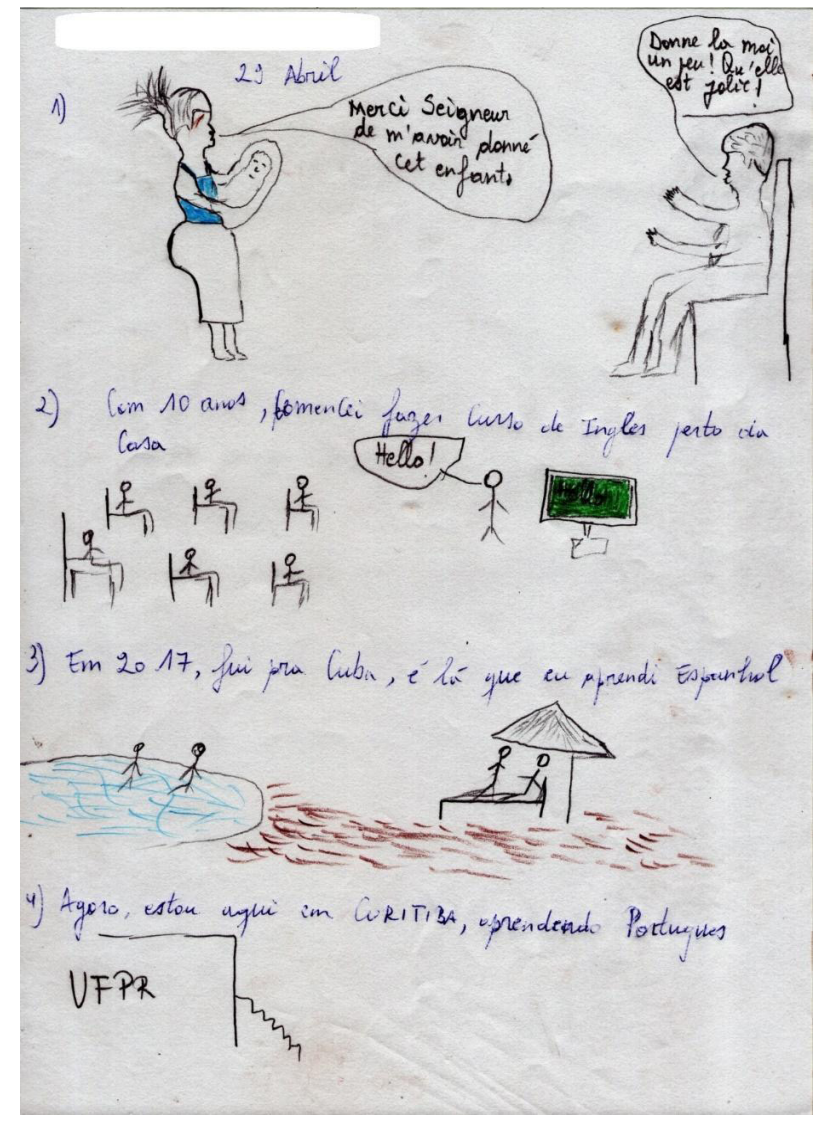

${ }^{8} \mathrm{O}$ retângulo em branco foi inserido no desenho pelas professoras para não identificar a aluna. 
\#PraCegoVer: Desenho colorido dividido em quatros partes de cima para baixo. Na primeira a expressão 22 de abril e o desenho de uma mulher com um bebê no colo, dela sai um balão em francês "Merci seigneur d'avoir donné cet enfant". A mulher leva o bebê para um homem sentado numa cadeira, ele está com os braços estendidos para frente e há um balão de uma fala "Donne la moi un peu! Qu'elle est jolie!". Segunda parte a frase: Com 10 anos comecei a fazer curso de inglês perto de casa. Desenho de uma sala de aula com vários alunos, um quadro e uma professora dizendo Hello! Terceira parte a frase: Em 2017 fui para Cuba, é lá que eu aprendi espanhol. Desenho de duas pessoas no mar e outras duas num quiosque com guarda-sol. Quarta parte, a frase: Agora estou aqui em Curitiba, aprendendo português. Desenho de uma construção com a logo UFPR e uma escadaria em frente.

Ainda em relação às análises, podemos ressaltar que, embora tenham sido selecionados apenas cinco desenhos para este artigo, observamos algumas representações mais ou menos transversais a todos os sujeitos. Como por exemplo: (i) a língua materna representada no ambiente familiar, algumas vezes com a ilustração de membros da família; (ii) a associação da língua inglesa ao ambiente escolar - há também a representação da aprendizagem do francês e do espanhol em contexto formal de ensino; (iii) o português representado pela UFPR; (iv) a associação das línguas às situações comunicativas (língua utilizada na família, na escola, na igreja, com os amigos, na universidade).

\section{CONSIDERAÇÕES FINAIS}

Embora a atividade com os desenhos tenha propiciado discussões profícuas e, também apresentado resultados, a nosso ver, bastante positivos, é importante mencionar que houve, no início, uma certa resistência de alguns alunos em realizar o desenho. Mas, após o término da atividade, todos entenderam melhor o objetivo da proposta e avaliaram terem sido proveitosas as reflexões oriundas dessa tarefa.

Com relação às análises dos desenhos, a maioria dos estudantes representou seu trajeto linguístico de maneira cronológica, alguns com maior detalhamento, apontando o ano do início da aquisição, aprendizagem ou contato com determinada língua. No entanto, é importante salientar que essa datação pode ignorar, em alguns casos, o fato de que nem sempre as línguas começam a fazer parte de nossa vida em um momento pontual.

No que diz respeito às emoções associadas às línguas (ARAGÃO, 2008; BARCELOS \& COELHO, 2010), temos apenas uma emoção negativa, de Maria (imagem 2), relacionada ao inglês e representada por um $X$, indicando que a aluna não gostava de estudar esse idioma. No entanto, essa língua não deixa de fazer parte de sua biografia linguística. Ainda no desenho de Maria, temos uma representação nostálgica, através da imagem da paisagem de seu país de origem, podendo ser associada, também, a sua língua materna. Com relação às emoções positivas, há, por exemplo, no desenho de Angela (imagem 1), a representação da aluna sorrindo em vários contextos linguísticos, especialmente, quando associada à série de televisão norueguesa "SKAN".

Revista X, v. 16, n. 2, p. 437-460, 2021. 
Quanto aos locais presentes nos desenhos, temos o ambiente familiar representado pela casa ou família, a escola ou curso de idiomas, a igreja, a 'rua' - fazendo referência às situações cotidianas, a praia associada ao país da língua ilustrada e, ainda, o Brasil e a UFPR. Assim, as associações das línguas a determinados locais e situações de usos nos revelam suas diferentes funções e estatutos na vida dos sujeitos.

Com relação às línguas representadas, uma vez que, com exceção do desenho de Maria, as demais biografias seguem uma ordem claramente cronológica, a primeira retratada é a língua materna, ilustrada no ambiente familiar. Já no desenho de Maria, a LM aparece sob a forma de texto de apresentação conectada a uma outra "língua" utilizada como código pelas crianças, a 'língua do Fi' (equivalente à 'língua do P' em português). Essa associação pode demonstrar que a aluna não trata as línguas de forma hierarquizada, pois coloca lado a lado um idioma e uma brincadeira de criança. Além disso, salientamos que existem línguas não representadas nos desenhos, apesar de fazerem parte do repertório linguístico dos alunos, como, por exemplo, o caso da aluna Judith.

Comum a todos os desenhos, foi a representação do inglês, sempre ilustrado de maneira relacionada ao ambiente escolar (com carteiras, professor, livros, o espaço físico da escola ou conteúdos lexicais, como as cores). Assim, podemos sugerir que os alunos desconsideram que a língua inglesa, em maior ou menor grau, permeia as sociedades (por meio das músicas, jogos, softwares, estrangeirismos, etc.), não estando presente apenas na escola.

Para a nossa pesquisa, são especialmente relevantes as representações linguísticas, pois essas nos dão indícios da consciência metalinguística dos alunos, podendo nos auxiliar a guiar nossas práticas pedagógicas em consonância com a SDL. Dentre as línguas ilustradas, além das LMs e idiomas do país, é importante salientar a presença de representações de línguas nas quais os alunos não possuem alto nível de proficiência. Como exemplo, temos na imagem 2 o desenho de um coração ao lado da palavra 'jabibi' que faz referência à língua árabe (habib), embora esteja grafada no alfabeto latino com uma interferência da fonética do espanhol. A aluna quis demonstrar para a colega síria que tinha algum conhecimento de sua língua materna.

Já no desenho de Angela (imagem 1), surge o exemplo do russo e do francês, línguas em que a aluna não possui nenhum nível de proficiência, mas às quais ela já esteve exposta através de filmes. Ainda na imagem 1, temos o norueguês, definido pela aluna como sua "língua de estimação", uma vez que a estudante se interessou por esse idioma através de uma série de televisão. Há, também, conforme já mencionado, um 
exemplo curioso que não diz respeito a uma língua propriamente dita, o caso da 'língua do fi', representada no desenho 2 .

Ainda com relação à consciência metalinguística do grupo analisado, é interessante notar, na imagem 3, como Jean posiciona as línguas de acordo com seu uso em cada tipo de contexto social e, também, de que forma essa ordenação muda ao longo do tempo. No entanto, ao final do desenho, ele representa todas as línguas de sua trajetória sem atribuir nenhuma posição, colocando-as em pé de igualdade no 'ambiente' que ele identifica como vida. No caso do desenho 4, Nádia representou, sem nomear, línguas com as quais ela ainda não teve contato, demonstrando uma abertura para novas experiências linguísticas. Porém, ela não retratou em sua ilustração, por exemplo, o espanhol, sendo essa a língua materna de muitos migrantes com os quais ela tem contato e que, em nosso entendimento, fazem parte, em alguma medida, de sua trajetória linguística.

Por fim, no desenho 5, de Judith, o que nos chamou a atenção, foi o fato de a estudante não mencionar línguas regionais com as quais ela teve contato no contexto familiar e em sua comunidade local, como o tshiluba, lingala, swahili e kikongo. Assim, a discente optou por representar apenas os idiomas francês, inglês, espanhol e português; o que nos faz refletir sobre o porquê dessa escolha: a opção foi de representar apenas as línguas oficiais e, consequentemente, de maior prestígio? Ou por não conceder um estatuto de igualdade a todas as línguas de seu repertório? Ou ainda a estudante não as reconhece como línguas de fato? Dessa maneira, pudemos verificar que os alunos possuem certo grau de consciência metalinguística, mas que ainda há trabalho a se fazer.

Assim, podemos concluir que o resultado final da atividade foi positivo, nos proporcionando trabalhar, através das narrativas visuais, com a sensibilização à diversidade linguística de cada sujeito, para então, discutir sobre essa nova empreitada que estávamos iniciando naquele momento: o aprendizado do português acadêmico.

Dessa maneira, a partir dos desenhos, pudemos fomentar uma discussão sobre uma sala de aula com alunos plurilíngues, para que, em primeiro lugar, se reconhecessem como tal e pudessem construir uma autoimagem positiva a nível afetivo e do reconhecimento do valor de seus repertórios linguísticos. Ao mesmo tempo, a atividade proporcionou o desenvolvimento de capacidades de reflexão sobre as línguas, possibilitando que, durante a apresentação dos desenhos pelos estudantes, eles se conscientizassem sobre como esses conhecimentos poderiam ser mobilizados para ajudá-los no aprendizado do português - e/ ou de outras línguas.

Dessa maneira, pudemos esclarecer que o aprimoramento da língua-alvo proposto pela disciplina recém-iniciada, não acarretaria, de nenhuma forma, em um apagamento 
de suas línguas e culturas, uma vez que suas competências plurilíngues e pluriculturais seriam valorizadas nesse contexto de ensino-aprendizagem (BLANCHET, 2015) ${ }^{9}$.

Por fim, como um possível desdobramento deste estudo, acreditamos ser importante sensibilizar não apenas nossos estudantes, mas também os professores - especialmente os de idiomas - e a comunidade da UFPR como um todo, através de campanhas institucionais, formações, palestras acerca dos pontos positivos de se possuir, em seu corpo discente, estudantes plurilíngues e pluriculturais. Entendendo a migração como oportunidade, e, assim, reforçando o compromisso de uma universidade inclusiva e democrática.

\section{REFERÊNCIAS}

ACNUR. ALTO COMISSARIADO DAS NAÇÕES UNIDAS PARA REFUGIADOS (ACNUR) / UNITED NATIONS HIGH COMMISSIONER FOR REFUGEES (UNHCR). Site oficial. Disponível em: <https://www.acnur.org/portugues/>. Acesso em: 2 jun. 2020.

ARAGÃO, R. Emoções e pesquisa narrativa: transformando experiências de aprendizagem. Revista Brasileira de Linguística Aplicada, v. 8, n. 2, p. 295-320, 2008.

ARMAND, F.; MARAILLET, E. Éducation interculturelle et diversité linguistique. Montréal: ÉLODIL, 2013. Disponível em: <https://www.elodil.umontreal.ca/fileadmin/ documents/Guides/eal/22-complet.pdf.> Acesso em: 15 jan. 2021.

BARCElOS, A.M.F.; COELHO, H.S.H. (Orgs.) Emoções, Reflexões e (trans) Form (ações) de Alunos, Professores. Campinas: Pontes Editores, 2010.

BLANCHET, P. Integração ou discriminação da pluralidade linguística na educação de línguas e pelas línguas: uma questão crucial entre ideologia, ética e didática. MOARARevista Eletrônica do Programa de Pós-Graduação em Letras, v. 42, p. 9-21, 2015. Disponível em: <https://periodicos.ufpa.br/index.php/moara/article/view/2053>. Acesso em: 18 jan. 2021.

BORTONI-RICARDO, S. M. O professor pesquisador: introdução à pesquisa qualitativa. São Paulo, SP: Parábola Editorial, 135 p. 2008.

CANDELIER, M. L'éveil aux langues à l'école primaire. Evlang: bilan d'une innovation européenne. Bruxelles, DeBoeck Supérieur, 384 p. 2003.

\footnotetext{
${ }^{9}$ Blanchet (2015) apresenta propostas didáticas para a integrar a pluralidade linguística e cultural dos estudantes no ensino de línguas e em uma educação humanista pelas línguas.
} 
CANDELIER, M. \& DE PIETRO, J.-F. (Coord.) Le CARAP - Une introduction à l'usage. Strasbourg: Conseil de 1'Europe. 2012. Disponível em: <www.carap.ecml.at>. Acesso em: 13 jun. 2020.

CANDELIER, M.; CAMILLERI-GRIMA, A.; CASTELLOTTI, V.; DE PIETRO, J.; LÖRINCZ, I.; MEISSNER, F.J.; SCHRÖDER-SURA, A.; NOGUEROL, A. Le CARAP: un cadre de référence pour les approches plurielles des langues et cultures. Compétences et ressources. Graz, Centre Européen pour les langues vivantes, Conseil de l'Europe, 104 p. 2012. Disponível em: <https://www.ecml.at/Portals/1/documents/ECML-resources/ CARAP-FR.pdf?ver=2018-03-20-120658-740>. Acesso em: 10 jul. 2020.

COSTE, D., MOORE, D. \& ZARATE, G. Compétence plurilingue et pluriculturelle. Vers un Cadre Européen Commun de référence pour l'enseignement et l'apprentissage des langues vivantes: études préparatoires. Strasbourg: Éditions du Conseil de l'Europe. 2009. Disponível em: <https://rm.coe.int/168069d29c >. Acesso em: 5 jun. 2020.

GEDIEL, J.A.P.; FRIEDRICH, T.S. (Orgs). Movimentos, Memórias e Refúgio: Ensaios sobre as Boas Práticas da Cátedra Sérgio Vieira de Mello (ACNUR) na Universidade Federal do Paraná. Curitiba: InVerso, 2020.

KALAJA, P.; MELO-PFEIFER, S. (Orgs.). Visualising multilingual lives: More than words. Bristol: Multilingual Matters, 2019.

KALAJA, P.; PITKÄNEN-HUHTA, A. (Orgs.). Visual methods in Applied Language Studies. Applied Linguistics Review, v. 9, n. 2-3 (Double special issue), 2018. Disponível em: $<$ https://jyx.jyu.fi/bitstream/handle/123456789/52967/kalajapitkanenhuhtaalrspecial. pdf? sequence $=2>$. Acesso em: 27 jul. 2020.

KUCHARCZYK, R.; SZYMANKIEWICZ, K. L'autonarration en tant que méthode d'investigation sur la compétence plurilingue, Studia Romanica Posnaniensia, 46/2, p. 81-97. 2019.

MELO-PFEIFER, S.; SCHMIDT, A. Integration as Portrayed in Visual Narratives by Young Refugees in Germany. In: Visualising Multilingual Lives More Than Words. Edited by Paula Kalaja and Sílvia Melo-Pfeifer. 2019.

MELO-PFEIFER, S. \& SCHMIDT, A. "Desenha-te a falar as línguas que conheces": imagens de crianças luso(fono)descendentes na Alemanha acerca da sua Competência Plurilingue. In: A. I. Andrade, Ma H. Araújo e Sá, R. Faneca, F. Martins, A. S. Pinho \& A. R. Simões (org.), A diversidade linguística nos discursos e nas práticas de educação e formação. Aveiro: Universidade de Aveiro, p. 159-182, 2014. 
MELO-PFEIFER, S.; SIMÕES, A.R. Métodos visuais no ensino-aprendizagem de línguas e na formação de professores. In: MELO-PFEIFER, S.; SIMÕES, A.R. (Org.). Plurilinguismo vivido, plurilinguismo desenhado: estudos sobre a relação dos sujeitos com as linguas. Santarém: ESE, 2017.

MOLINIÉ, M. Biographie langagière et apprentissage plurilingue. Le Français dans le Monde Recherches et Applications, $\mathrm{n}^{\circ}$ 39. Paris: CLE International, 2006.

MOLINIÉ, M. Biographie Langagière in DELORY-MOMBERGER, C. Vocabulaire des histoires de vie et de la recherche biographique. ERES. p. 300-303. 2019.

PERREGAUX, C. (Auto)biographies langagières en formation et à l'école: pour une autre compréhension du rapport aux langues. VALS-ASLA, 76, 81-94. 2002.

RUANO, B.P. Programa Reingresso UFPR - aproveitamento de vagas remanescentes para a reinserção acadêmica de migrantes e refugiados: ações de acolhimento. $432 \mathrm{p}$. Tese (Doutorado em Estudos Linguísticos) - Universidade Federal do Paraná, Curitiba, 2019.

UFPR. Resolução 13/14. Aprova normas para acesso de migrantes regularmente admitidos no Brasil. 2014. Disponível em: http://www.soc.ufpr.br/portal/wp-content/ uploads/2016/07/resolucao_cepe_09072014-902.pdf Acesso em: 15 jan. 2021.

UFPR. Resolução 02/16. Estabelece normas para a revalidação de diplomas de graduação expedidos por estabelecimentos estrangeiros de ensino superior requerida por migrantes regularmente admitidos no Brasil e portadores do estado de refugiado ou de visto humanitário. 2016. Disponível em: http://www.soc.ufpr.br/portal/wp-content/ uploads/2016/07/cepe-0216-Revalida\%C3\%A7\%C3\%A3o-de-Diplomas-Refugiados. pdf Acesso em: 15 jan. 2021.

UFPR. Resoluçãon ${ }^{\circ} 63 / 18$. Estabelece e aprova a criação de vagas suplementares destinadas a migrantes em condição de refugiado ou com visto humanitário em todos os cursos de UFPR. 2018. Disponível em: http://www.soc.ufpr.br/portal/wp-content/uploads/2018/11/ cepe-63-18-vagas-suplementares-migrantes.pdf Acesso em: 10 jan. 2021.

UFPR. Resolução 59/19. Institui o Programa de Formação Suplementar: Ciclo de Acolhimento Acadêmico para Estudantes Refugiados (PFS-Refugiados) destinado aos estudantes admitidos na Universidade Federal do Paraná na condição de refugiados. 2019b. Disponível em: http://www.soc.ufpr.br/portal/wp-content/uploads/2020/02/ cepe5619.pdf Acesso em: 10 jan. 2021.

Recebido em: 12 out. 2020.

Aceito em: 26 jan. 2021. 